\title{
MORFOANATOMIA FOLIAR DE Palicourea longepedunculata Gardiner (RUBIACEAE) ${ }^{1}$
}

\author{
Zefa Valdivina Pereira ${ }^{2}$, Renata Maria Strozi Alves Meira ${ }^{3}$ e Aristéa Alves Azevedo ${ }^{3}$
}

\begin{abstract}
RESUMO - O gênero Palicourea - tribo Psychotrieae - compreende cerca de 200 espécies e destaca-se por apresentar alcalóides indólicos muitas vezes tóxicos para bovinos. O objetivo do presente trabalho foi contribuir para o conhecimento da família Rubiaceae, enfatizando os aspectos da morfoanatomia foliar de Palicourea longepedunculata. O material foi coletado na Reserva Florestal Mata do Paraíso (RFMP), município de Viçosa, Minas Gerais, e amostras-testemunha foram depositadas no herbário VIC. Folhas provenientes do quarto nó foram fixadas em $\mathrm{FAA}_{50}$ e conservadas em etanol $70 \%$. Seções transversais e longitudinais do pecíolo e da lâmina foliar foram obtidas em micrótomo de mesa para montagem de lâminas permanentes, conforme metodologia usual. As folhas são simples, opostas, inteiras, ovais lanceoladas, dorsiventrais e hipoestomáticas. A epiderme do pecíolo e da lâmina foliar é uniestratificada, papilosa na face adaxial da folha e recoberta por cutícula delgada. Os estômatos são paracíticos e ocorrem no mesmo nível das demais células epidérmicas. O mesofilo é constituído por uma camada de parênquima paliçádico e de várias de parênquima lacunoso. Na face adaxial e abaxial da nervura mediana e no bordo da lâmina observa-se colênquima subepidérmico. Um feixe vascular do tipo colateral, em forma de "U", distribui-se ao longo do pecíolo e da nervura mediana, acompanhado, invariavelmente, por dois feixes menores localizados lateralmente. No córtex do pecíolo e da nervura mediana observa-se aerênquima. As características anatômicas seguem o padrão descrito para as Rubiaceae, e algumas delas são interpretadas como adaptações a ambientes úmidos e sombreados no qual a espécie ocorre.
\end{abstract}

Palavras-chave: Anatomia foliar, Palicourea, Rubiaceae e folhas de sombra.

\section{LEAF MORPHO -ANATOMY OF Palicourea longepedunculata Gardiner (RUBIACEAE)}

\begin{abstract}
The genus Palicourea - Psychotrieae tribe, comprising around 200 species of shrubs and small trees, is distributed from Mexico to northeastern Argentina. This group particularly stands out for containing indol alkaloids, which are often toxic to cattle. The aim of this work was to contribute to the knowledge of the family Rubiaceae, emphasizing aspects of the leaf morpho-anatomy of Palicourea longepedunculata. The botanic material was collected in Mata do Paraíso Forest Reserve (RFMP), in Viçosa, Minas Gerais, Brazil, and the control was kept in the VIC herbarium. Fully-expanded leaves from the $4^{\text {th }}$ node were fixed in FAA ${ }_{50}$ and preserved in ethanol 70\%. Cross and longitudinal sections of the petiole and leaf blade were obtained by means of rotatory microtome, and permanent slides were mounted according to the usual methodology. The leaves are simple, opposite, whole, oval lanceolate, dorsiventral and hypostomatic. The petiole and leafblade epidermis is unilayered, with a papillose upper side, which is covered by a thin cuticle. The paracytic stomata occur at the same level as the other epidermic cells. The mesophyll is constituted by a single layer of palisade parenchyma and several layers of spongy parenchyma. Subepidermic chollenchyma is observed on the upper and lower sides of the midrib and on the margin of the blade. The " $U$ " shaped collateral vascular bundle is distributed along the petiole and midrib, and always sided by two smaller vascular bundles, laterally located. Cortical aerenchyma is observed in the petiole and midrib. The anatomical characteristics follow the pattern described for the Rubiaceae with some of them being interpreted as adaptations to moist and shady environments where the species occurs.
\end{abstract}

Key words: leaf anatomy, Palicourea, Rubiaceae and shade leaves.

1 Recebido para publicação em 28.6.2002.

Aceito para publicação em 4.11.2003.

2 Mestrado em Botânica, bolsista CNPq/CAPES; ${ }^{3}$ Professora do Dep. de Biologia Vegetal da Universidade Federal de Viçosa - UFV, 36570-000 Viçosa-MG, <rmeira@ufv.br>. 


\section{INTRODUÇÃO}

A Rubiaceae Juss. é a quarta maior família das angiospermas, pois apresenta cerca de 550 gêneros e 9.000 espécies (Robbrecht, 1993) de ampla distribuição, principalmente nas regiões tropicais e subtropicais (Barroso et al., 1991; Judd et al., 1999).

O gênero Palicourea - tribo Psychotrieae - compreende cerca de 200 espécies de arbustos e pequenas árvores, distribuídas do México até o nordeste da Argentina (Taylor, 1997). Este gênero destaca-se por apresentar alcalóides indólicos muitas vezes tóxicos para bovinos, porém testes de laboratório realizados com Palicourea longepedunculata demonstraram a ausência dessas substâncias (Pereira, 1992). Schumann (1891) foi o primeiro a realizar um estudo sistemático em Rubiaceae, quando caracterizou o gênero Psychotria, separando-o de Palicourea. Desde então, não há consenso quanto às características mais adequadas na separação entre as espécies incluídas nestes dois gêneros, considerados morfologicamente muito semelhantes (Standley, 1936, 1938; Steyermark, 1972; Taylor, 1989, 1993, 1996).

Palicourea longepedunculata Gardiner é uma espécie que cresce no interior da mata. Nas florestas virgens, onde a vegetação arbustiva desaparece por força da cobertura espessa da folhagem das árvores, esta espécie é encontrada apenas nas bordas ou clareiras (Hoehne, 1932).

Dentre os trabalhos realizados com as Rubiaceae, além das obras de Solereder (1908) e Metcalfe \& Chalk (1950), destacam-se os de ACCORSI $(1947,1949)$ sobre os estômatos e as características morfoanatômicas e citológicas da epiderme foliar, da face abaxial, de várias espécies da família. Barros (1959) relatou a ocorrência de domácias em mais de 600 espécies, e Lersten (1974) fez referência à morfologia e à distribuição de coléteres e de cristais. Em trabalhos recentes foi descrita a anatomia foliar das espécies incluídas na sessão III do gênero Relbunium (Nunes et al., 1994), de Psychotria tenuinervis, de Psychotria stenocalyx (Gomes et al., 1995) e de Bathysa stipulata (Nascimento et al., 1996).

Apesar da grande diversidade desta família, são poucos os dados sobre sua anatomia. Sendo assim, o objetivo deste trabalho foi apresentar aspectos da morfoanatomia foliar de Palicourea longepedunculata que poderão servir de subsídio para a taxonomia do gênero, bem como indicar as estratégias adaptativas da espécie,

R. Árvore, Viçosa-MG, v.27, n.6, p.759-767, 2003 tipicamente encontrada em sub-bosque de florestas tropicais, correlacionando as características estruturais com o ambiente onde a planta ocorre.

\section{MATERIAL E MÉTODOS}

Palicourea longepedunculata tem hábito escandente, é típica de interior de mata e ocorre na Reserva Florestal Mata do Paraíso (RFMP), município de ViçosaMG, situado nas as coordenadas $20^{\circ} 45^{\prime} \mathrm{S}$ e $42^{\circ} 55^{\prime} \mathrm{W}$, a uma altitude de $690 \mathrm{~m}$. Essa reserva é uma área de preservação ambiental vinculada ao Departamento de Engenharia Florestal da Universidade Federal de Viçosa, Minas Gerais. Segundo Rizzini (1992), a vegetação natural da reserva faz parte dos domínios da Floresta Atlântica. A floresta primária foi desmatada durante a segunda metade da década de 50, tendo sido sucessivamente substituída por cultivos, principalmente de café, e por pastagem (Volpato, 1994). Atualmente a vegetação encontra-se em diversos estádios sucessionais, não tendo sido registrada a ocorrência de incêndio ou extração de madeira na área desde 1963; no entanto, não existem informações confiáveis sobre idade da vegetação ou perturbações ocorridas anteriormente (Leal Filho, 1992).

Os espécimes-testemunha foram herborizados e incluídos no acervo do Herbário VIC, da Universidade Federal de Viçosa, sob os números 26953, 26954 e 26955.

Folhas completamente expandidas, provenientes do quatro nó, foram fixadas em FAA (formaldeído, ácido acético e etanol 50\%, 1:1:18, v/v), por 48 horas, e armazenadas em etanol 70\% (Johansen, 1940). Seções transversais e longitudinais do pecíolo e da lâmina foliar (regiões basal, mediana e apical) foram obtidas com o uso de micrótomo de mesa; os cortes foram corados com azul-de-astra e safranina (solução alcoólica) ou fucsina básica (Kraus \& Arduin, 1997) e as lâminas foram montadas em bálsamo-do-canadá. Fragmentos da lâmina foliar foram diafanizados, utilizando-se solução de ácido clorídrico e peróxido de hidrogênio, 1:1, hidróxido de sódio $10 \%$ e cloral hidratado $25 \%$, intercalados por sucessivas lavagens em água destilada e corados com safranina e azul-de-astra (Kraus \& Arduin, 1997).

A classificação dos estômatos foi feita de acordo com Wilkinson (1979), a do sistema vascular de acordo com o esquema proposto por Howard (1979) e a descrição morfológica seguiu as recomendação de Radford et al. (1974). 
Os cortes foram submetidos aos seguintes reagentes: lugol para identificação do amido; sudan III glicerinado para substâncias lipídicas; floroglucina ácida para lignina; e vermelho-de-rutênio para substâncias pécticas (Jensen, 1962).

\section{RESULTADOS}

Palicourea longepedunculata é uma planta encontrada no interior da mata, fazendo parte da sinusia arbustiva, o que leva ao sombreamento de suas folhas, provocado pelas plantas dos estratos superiores. As folhas são opostas, com cerca de $180 \mathrm{~mm}$ de comprimento, de consistência membranácea, coloração verde-escura, forma oval-lanceolada, base obtusa e ápice agudo. O padrão de venação é do tipo broquidódromo (Figura 1), caracterizado pela união das nervuras laterais, formando arcos proeminentes próximos à margem.

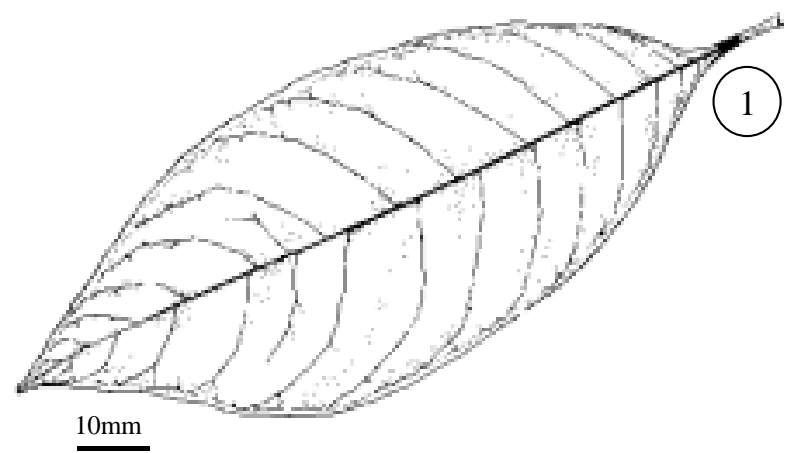

Figura 1 - Pali courea longepedunculata - fol ha com padrão de venação broquidódromo.

Figure 1 - Palicourea Iongepedunculata leaf: brochidodromous venation.

O pecíolo apresenta formato cilíndrico, sendo a face adaxial das regiões basal e distal caracterizada pela presença de projeções laterais, que delimitam uma região levemente côncava (Figuras 2 e 3 ). A epiderme uniestratificada apresenta pêlos tectores unicelulares (Figura 5).

A região cortical do pecíolo encontra-se dividida em duas porções: uma periférica, constituída por cinco a sete camadas de colênquima do tipo angular, e uma interna, constituída por parênquima (Figuras 2 e 3); na região próxima ao sistema vascular, as células parenquimáticas dispõem-se frouxamente, originando um aerênquima (Figuras 2 e 3). Na porção basal do pecíolo o aerênquima é menos proeminente que na porção apical (Figuras $2 \mathrm{e}$ 3). Junto ao floema, as células parenquimáticas apresentam paredes mais espessas e de menores dimensões. As células parenquimáticas, de paredes delgadas, localizadas próximo ao sistema vascular, possuem numerosos grãos de amido. Idioblastos contendo ráfides são comuns na região cortical (Figura 4).

O sistema vascular do pecíolo é constituído por um feixe central colateral, na forma de "U", sendo acompanhado, em toda a extensão, por dois feixes laterais menores (Figura 2).

Na lâmina foliar a epiderme é papilosa e uniestratificada (Figuras 7 e 8), recoberta por uma cutícula delgada e lisa. Na face adaxial as paredes anticlinais das células epidérmicas variam de retas a levemente onduladas (Figura 11), enquanto na face abaxial essas paredes são sinuosas (Figura 12). Os estômatos são do tipo paracítico (Figura 12), situados somente na face abaxial da folha e no mesmo nível das demais células epidérmicas (Figura 7).

O mesofilo é dorsiventral, representado por uma camada de parênquima paliçádico e por vários estratos de parênquima lacunoso, constituído por células de parede delgada (Figura 7). Idioblastos contendo ráfides são comuns no mesofilo.

A organização do sistema vascular na nervura mediana (Figura 6) repete o padrão descrito para o pecíolo (Figuras 2 e 3 ). As células parenquimáticas próximas ao feixe possuem numerosos grãos de amido (Figuras 6 e 9) no terço basal e mediano; já no terço apical estes são menos evidentes. Na nervura mediana (Figura 6) o aerênquima é mais proeminente do que o observado na porção basal do pecíolo (Figura 3); algumas células parenquimáticas do córtex apresentam paredes com espessamento em rede (Figuras 9 e 10); e o tecido de sustentação está representado por colênquima angular (Figuras 6 e 10) e fibras (Figura 9). O colênquima do tipo angular ocorre nas faces adaxial e abaxial da nervura mediana (Figura 6) e na margem da lâmina (Figura 8), enquanto as fibras distribuem-se junto ao floema (Figura 9).

\section{DISCUSSÃO E CONCLUSÕES}

O estudo anatômico da folha de Palicourea longepedunculata revelou que sua organização reflete as características gerais da família Rubiaceae, citadas por Solereder (1908) e Metcalfe \& Chalk (1950).

R. Árvore, Viçosa-MG, v.27, n.6, p.759-767, 2003 


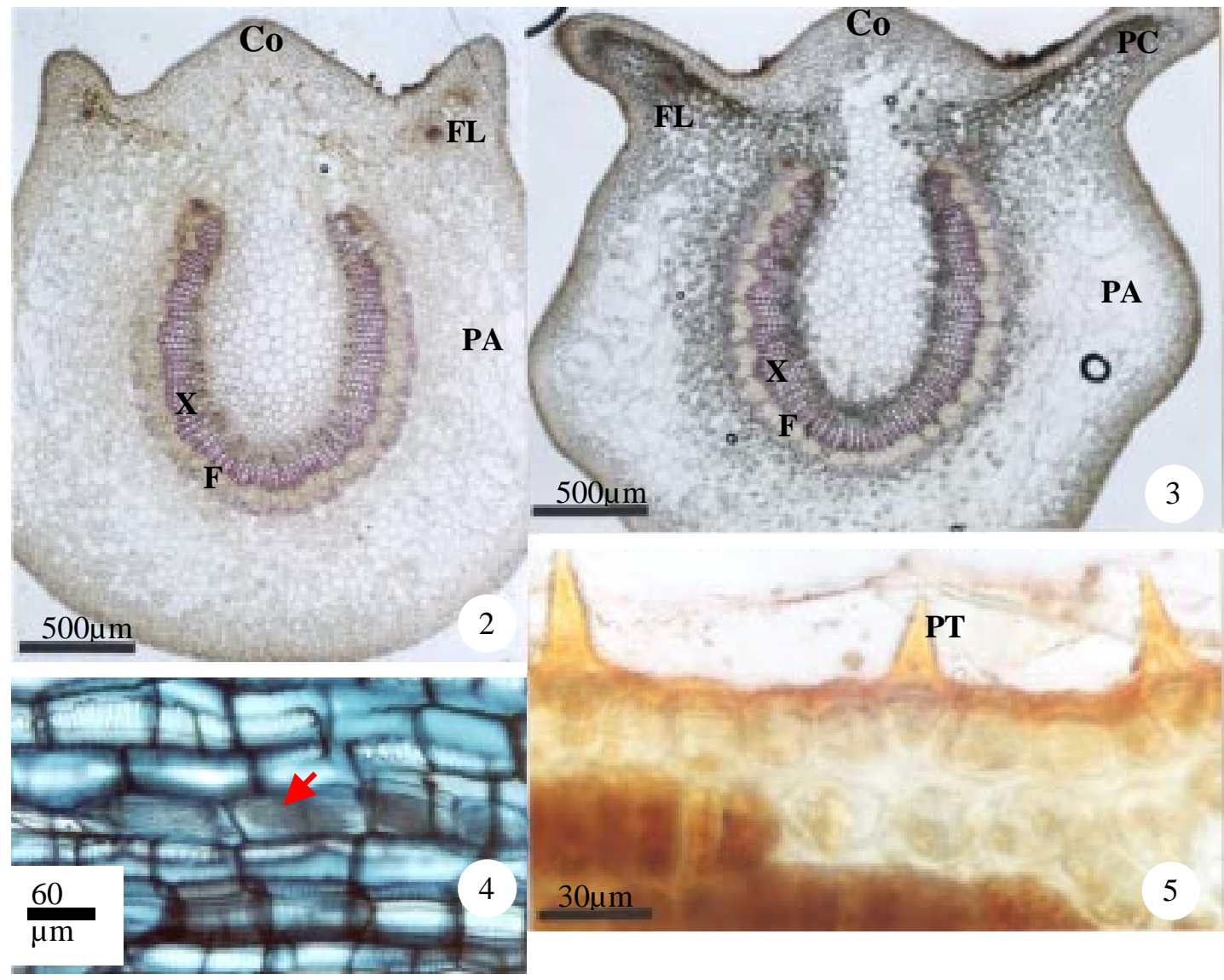

Co - colênquima, F - floema, FL - feixe lateral, PA - parênquima aerífero (aerênquima), PC - parênquima clorofiliano, PT - pêlo tector, $\mathrm{X}$ - xilema, seta - ráfides.

Co- collenchyma, F-phloem, FL - lateral bundle PA - aerenchyma, $P C$ - chlorenchyma, PT - tector hair, X - xylem, arrow raphides.

Figuras 2 - 5 - Palicourea longepedunculata - cortes, transversais e longitudinal, do pecíolo. 2-3. Regiões basal e apical, respectivamente, submetidas à floroglucina ácida. 4. I dioblasto cortical contendo ráfides (corte longitudinal corado com safranina e azul-de-astra). 5. E piderme adaxial, tratada como Sudan III.

Figures 2 - 5 - Palicourea longepedunculata - cross and longitudinal sections of the petiole. 2-3. Apex and basal portion, treated with acid floroglucin. 4. Cortical idioblast containing raphides (longitudinal section stained with safranin and astra blue). 5. Adaxial epidermis treated with Sudan III.

$\mathrm{Na}$ espécie em estudo, o sistema vascular tanto do pecíolo como da lâmina foliar está organizado na forma de "U", apresentando dois feixes laterais menores, conforme mencionado por Metcalfe \& Chalk (1950). Este mesmo padrão foi relatado para Psychotria tenuinervis, P. stenocalyx, P. nuda e P. leicarpa (Vieira et al., 1992; Gomes et al., 1995).

A organização vascular ao longo do pecíolo é constante, porém existem variações dentro da família.
Vieira (1988) descreveu a presença de um feixe mediano com a forma de um arco, com as extremidades fortemente fletidas em Tocoyena bullata. Assim, as extremidades dos feixes aproximam-se progressivamente até se encontrarem, formando um círculo na região distal do pecíolo ou no terço basal da lâmina foliar. Feixe vascular na forma de círculo foi observado por Mariani (1908), para a maioria das espécies de Coffea, bem como por Morretes (1966), para Tocoyena brasiliensis, e por Nascimento et al. (1996), para Bathysa stipulata. 
O aerênquima observado na região cortical, da nervura mediana e do pecíolo, também é citado por Gomes et al. (1995) para Psychotria tenuinervis e P. stenocalyx. Esse aerênquima, possivelmente, contribui para diminuir o peso específico das folhas, já que a espécie apresenta folhas relativamente grandes e tem hábito arbustivo escandente.
O padrão de distribuição dos tecidos de sustentação (colênquima e esclerênquima) observado em $P$. longepedunculata foi semelhante ao relatado por Gomes et al. (1995) para Psychotria tenuinervis e $P$. stenocalyx. Entretanto, Vieira $(1986,1988)$ observou que, em Diodia radula e Tocoyena bullata, o bordo foliar é ocupado por parênquima, assim como em Bathysa
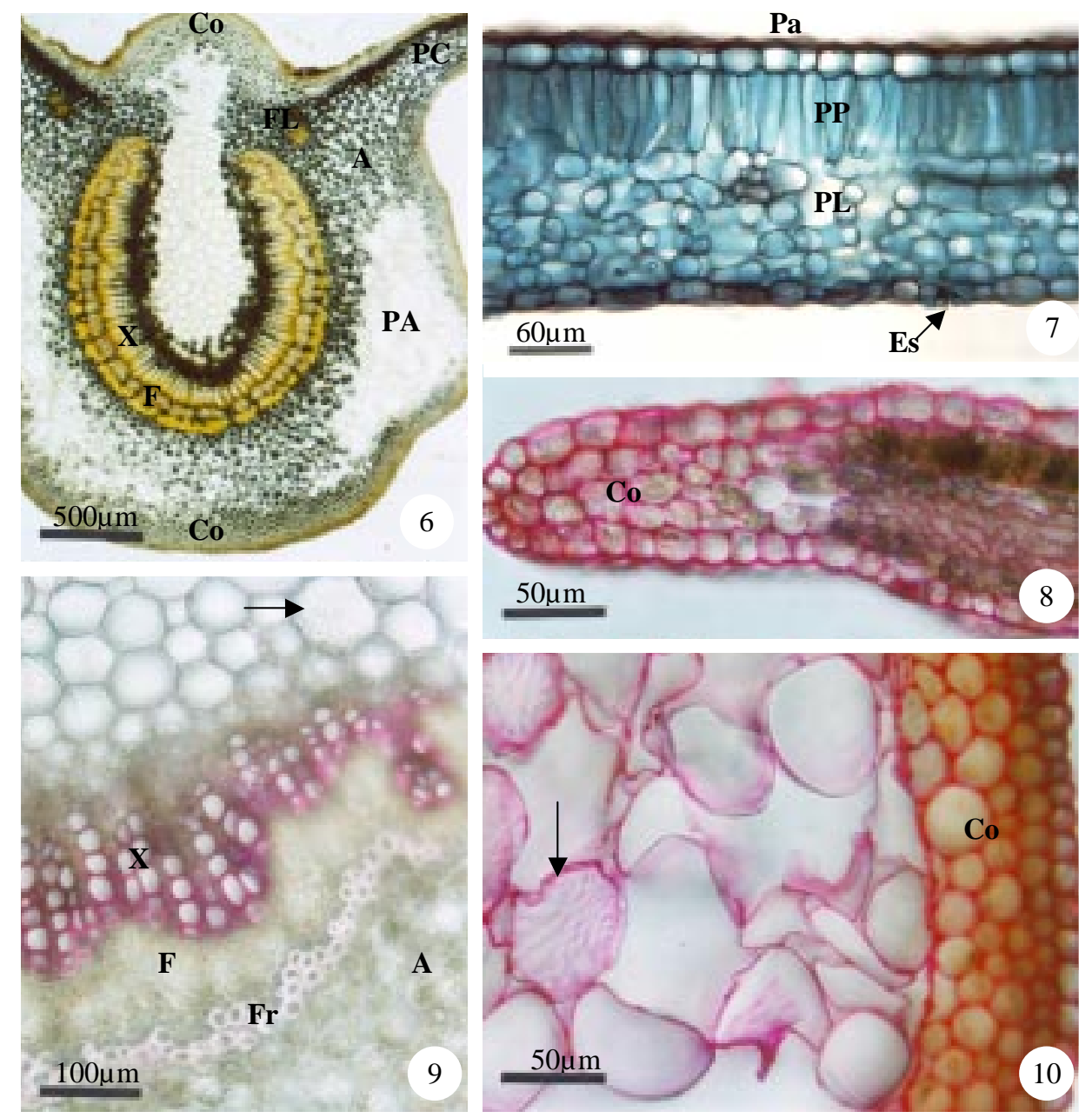

A - células com amido, Co - colênquima, Es - estômatos, F - floema, FL - feixe lateral, Fr - fibras, Pa - papilas, PA - parênquima aerífero (aerênquima), PC - parênquima clorofiliano, PL - parênquima lacunoso, PP - parênquima paliçádico, X - xilema. Seta espessamento da parede em rede.

A - cells with starch, Co-collenchyma, Es-stomata, F-phloem, FL-lateral bundle, Fr-fibers, Pa-papillae, PA-aerenchyma, $P C$ - chlorenchyma, $P L$ - spongy parenchyma, PP - palisade parenchyma, $X-x y l e m$. Arrow - reticulate cell wall thickening.

Figuras 6 - 10 - Palicourea longepedunculata - cortes transversais da lâmina foliar. 6, 9 e 10. Nervura mediana. 7. Mesofilo. 8. Margem. 6. Corte tratado com Lugol. 7. Corte corado com fucsina básica e azul-de-astra. 8 a 10. Cortes corados com vermelho-de-rutênio.

Figures 6-10- Palicourea longepedunculata - leaf cross sections. 6, 9 and 10. Midrib. 7. Mesophyll. 8. Margin. 6. Cross section treated with Lugol. 7. Section stained with basic fucsin and astra blue. $\mathbf{8}$ to 10. Sections stained with ruthenium red. 
stipulata (Nascimento et al., 1996). As fibras encontramse associadas ao sistema vascular, como citado por Metcalfe \& Chalk (1950) para a família Rubiaceae.

As células epidérmicas da face abaxial das folhas de $P$. longepedunculata apresentam contorno sinuoso, enquanto as da face adaxial têm contorno liso a levemente ondulado. Isanogle (1944) relatou que as folhas de sombra apresentam paredes anticlinais sinuosas, porém Vieira et al. (1992) observaram células epidérmicas com contorno reto em plantas de sombra de Psychotria nuda e P. leiocarpa. Vieira (1988) observou em Tocoyena bullata, planta de sol, paredes anticlinais da face abaxial com contorno sinuoso. Assim, acredita-se que outros fatores, além da luz, possam influenciar a expressão deste caráter. Em geral, em plantas de sol e de ambientes xéricos as células epidérmicas, especialmente as da face adaxial, apresentam contorno reto; nas plantas de sombra a ocorrência de células com contorno sinuoso, em ambas as faces da folha, é mais comumente observada (Wilkinson, 1979). Nas folhas de sol, a cutícula e as paredes celulares se espessam e ficam rígidas mais rapidamente, ao contrário do que ocorre nas folhas de sombra, nas quais as paredes celulares permanecem delicadas e plásticas por mais tempo, favorecendo o desenvolvimento de ondulações (Watson, 1942).

Com relação à ocorrência de uma cutícula delgada e lisa nas folhas, as informações são conflitantes, pois Accorsi (1947) observou a presença de cutícula lisa em 520 das 601 espécies de Rubiaceae estudadas e Holm (1907) citou cutícula estriada para a epiderme adaxial de Houstonia coerulea e Mitchella repens. Em Diodia teres, o autor ressaltou que tais estrias epicuticulares só ocorrem na nervura. Bergen (1904) afirmou que as folhas de sol de Pistacia apresentam cutícula estriada, enquanto nas de sombra a cutícula é lisa. Analisando 226 espécies de dicotiledôneas, Dunn et al. (1965) registraram a ocorrência de cutícula enrugada na maioria das espécies de ambiente xérico e de cutícula lisa para espécies mesófitas ou hidrófitas. Considerando que Palicourea longepedunculata é uma planta de interior de mata, os dados reforçam tanto a predominância desta característica para a família, quanto a sua correlação com o ambiente úmido e sombreado.

Estômatos paracíticos, distribuídos apenas na face abaxial, foram descritos por Solereder (1908) como sendo o tipo de estômato mais comum para a família Rubiaceae. Coutinho (1962) ressaltou que folhas hipoestomáticas são comuns em espécies das florestas pluviais e estacionais

R. Árvore, Viçosa-MG, v.27, n.6, p.759-767, 2003 tropicais e que tal fato pode representar uma proteção contra o recobrimento e a obliteração das fendas estomáticas por pequenos musgos, hepáticas e fungos comuns nesse ambiente.

A presença de tricomas tectores unisseriados também foi observada por Salatino et al. (1986), para Tocoyena formosa, e por Nascimento et al. (1996), para Bathysa stipulata, porém nestas espécies os tricomas apresentavam ornamentação verrucosa, fato este não constatado para a espécie estudada.
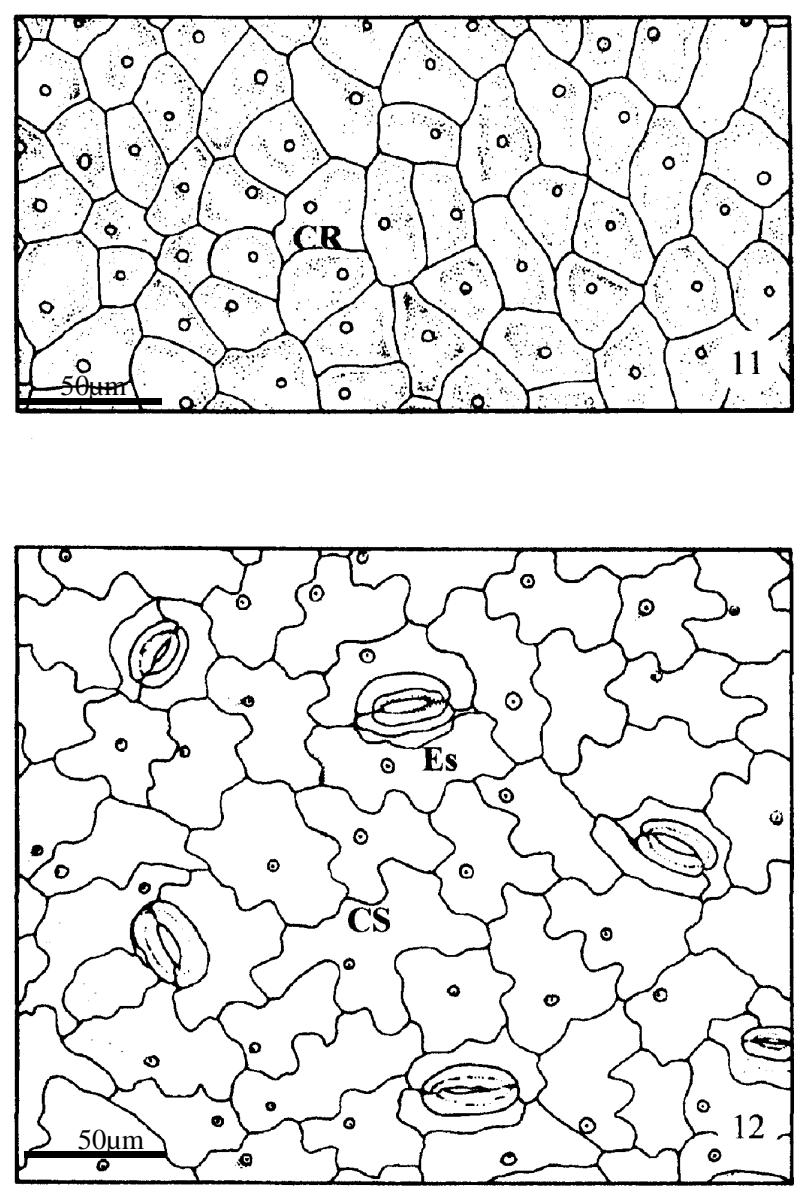

Figuras 11 e 12 - Palicourea longepedunculata - epiderme foliar, em vista frontal. 11. Células epidérmicas da face adaxial com as paredes anticlinais retas (CR). 12. Face abaxial com células de paredes anticlinais sinuosas (CS) e estômatos (Es)

Figures 11 and 12 - Palicourea longepedunculata - leaf epidermis, frontal view. 11. Epidermic cells of theadaxial wall with straight anticlinal walls (CR). 12. Abaxial surface with anticlinal sinuous cell walls (CS) and stomata (Es). 
A função dos tricomas tectores depende do órgão onde se encontram, de sua morfologia, de sua densidade e até mesmo de sua orientação, isto é, do ângulo de inclinação. Tricomas tectores densamente distribuídos em folhas e caules podem servir como uma barreira mecânica contra temperaturas extremas, alta intensidade luminosa, perda excessiva de água, entre outros fatores (Werker, 2000). Entretanto, em muitas plantas os tricomas aumentam a transpiração, porque ampliam a superfície de evaporação (Jonhson, 1975).

A epiderme da face adaxial de Palicourea longepedunculata caracteriza-se pela presença de papilas, estruturas estas também encontradas por Vieira et al. (1992) na epiderme da face adaxial de Psychotria leiocarpa e por Gomes et al. (1995) para Psychotria tenuinervis e P. stenocalyx. Wilkinson (1979) afirmou que as papilas podem ter superfície lisa, estriada ou verrucosa. Uphof (1962) sugeriu que as células papilosas da epiderme agem como lentes, convergindo os raios luminosos para o interior do mesofilo, conforme demonstrado por Bone et al. (1985). Assim, as papilas representam um mecanismo adaptativo importante para suprir as necessidades da fotossíntese, visto que no interior da floresta a luminosidade é reduzida.

Uphof (1962) relatou que, devido à intensa pluviosidade nas florestas tropicais, a superfície das folhas é coberta por uma fina camada de água. As papilas, com suas extremidades projetadas acima do nível da água, dispondo-se como ilhas isoladas, possibilitariam a continuidade do processo de absorção de energia luminosa, além da captação de estímulos luminosos.

O mesofilo do tipo dorsiventral corresponde ao padrão característico para a família Rubiaceae (Metcalfe \& Chalk, 1950). Vários autores, como Wylie (1951), Jackson (1967) e Costa (1989), em seus estudos sobre a influência da luz na estrutura foliar, afirmaram que o número de estratos de parênquima paliçádico é maior nas folhas de sol do que nas de sombra. Parênquima paliçádico pluriestratificado é mencionado por Vieira (1988) para folhas de sol de Tocoyena bullata. Palicourea longepedunculata apresenta parênquima paliçádico uniestratificado, característica típica de folhas de sombra, de acordo com as afirmações dos autores supracitados. Cabe ressaltar que espécies de Palicourea também são encontradas em outros tipos de formações vegetacionais, como Palicourea rigida, que ocorre no cerrado. Desta forma, é de suma importância a realização de estudos anatômicos com as espécies do gênero para verificar a real influência destas características na adaptação das espécies.

Palicourea longepedunculata apresenta numerosos idioblastos contendo ráfides, referidos também por Lersten (1974) e Morretes (1980) para espécies de Rubiaceae. Já os coléteres e domácias, que são estruturas comuns na família (Barros, 1959; Lersten, 1974), ainda não foram relatados no gênero Palicourea.

As características observadas na folha de Palicourea longepedunculata, como folha de consistência membranácea e coloração verde-escura, epiderme papilosa com cutícula delgada, tecido mecânico moderadamente presente, rede de nervuras pouco densa e tecido paliçádico uniestratificado, estão correlacionadas com ambientes úmidos e sombreados, como também relatado por Weaver \& Clements (1944), Rizzini (1976), Cutter (1986) e Hart (1988).

\section{AGRADECIMENTO}

À Rosane Cruz Portugal e Zilda Alzira Soares, funcionárias do Laboratório de Anatomia Vegetal do Departamento de Biologia Vegetal - UFV, pelo apoio técnico; e ao CNPq e à CAPES, pela bolsa concedida.

\section{REFERÊNCIAS BIBLIOGRÁFICAS}

ACCORSI, W. R. Ocorrência das células anexas dos estômatos na família Rubiaceae. Anais da Escola Superior de Agricultura “Luiz de Queiroz”, v . 4, p. 421-436, 1947.

ACCORSI, W. R. Características morfológicas, anatômicas e citológicas da epiderme inferior da folha das Rubiaceae. Lilloa, v. 16, p. 5-59, 1949.

BARROS, M. A. A. Ocorrência das domácias na família Rubiaceae. Anais da Escola Superior de Agricultura “Luiz de Queiroz”, v. 16, p. 331-337, 1959.

BARROSO, G. M. et al. Sistemática de angiospermas do Brasil. Viçosa, MG: Universidade Federal de Viçosa, 1991. v.3. 326 p.

BERGEN, J. Y. Transpiration of sun leaves and shade leaves of Olea europaea and other broad-leaved evergreens. Botanical Gazette, v. 38, p. 285-296, 1904.

BONE, R. A.; LEE, D. W.; NORMAN, J. M. Epidermal cells functioning as lenses in leaves of tropical rain-forest shade plants. Applied Optics, v. 24, n. 10, p. 1408-1412, 1985.

R. Árvore, Viçosa-MG, v.27, n.6, p.759-767, 2003 
COSTA, C. G. Morfologia e anatomia dos órgãos vegetativos em desenvolvimento de Marcgravia polyanta. 1989. 106 f. Tese (Doutorado em Botânica) - Universidade Estadual de São Paulo, São Paulo, 1989.

COUTINHO, L. M. Contribuição ao conhecimento da mata pluvial tropical. Boletim da Faculdade de Filosofia, Ciências e Letras da Universidade de São Paulo 305, Botânica, v. 18, p. 1-219, 1962.

CUTTER, E. G. Anatomia vegetal. São Paulo: Roca, 1986. $304 \mathrm{p}$.

DUNN, D. B.; SHARMA, G. K.; CARPBELL, C. C. Stomatal patterns of dicotyledons and monocotyledons. Am. Midl. Naturalist, v. 74, p. 185-195, 1965.

GOMES, D. M. S.; MANTOVANI, A.; VIEIRA, R. C. Anatomia foliar de Psychotria tenuinervis Mill. Arg. e P. stenocalyx Miill. Arg. (Rubiaceae) Arquivos de Biologia e Tecnologia, v. 38, n. 1, p. 15-33, 1995.

HART, J. W. Light and plant growth. London: Unwin Hyman, 1988. 204p.

HOEHNE, F. C. Plantas tóxicas e suspeitas da Flora Brasílica Palicourea marcgravii St. Hil. Revista Ind. Animal, v. 2, n. 8, p. 875-881, 1932.

HOLM, T. Rubiaceae: Anatomical studies of North American representatives of Cephalanthus, Oldenlandia, Houstonia, Mitchella, Diodia, and Galium. Botanical Gazette, v. 43, p. 153-189, 1907.

HOWARD, R. A. The petiole. In: METCALFE, C. R.; CHALK, L. (Eds.) Anatomy of the Dicotyledons. Systematic Anatomy of the leaf and stem. Oxford: Clarendon Press, 1979. v.1. p. 88-96.

ISANOGLE, I. T. Effect of controlled shading upon the development of leaf structure in two deciduous tree species. Ecology, v. 25, p. 409-413, 1944.

JACKSON, L. W. R. Effect of shade on leaf structure of deciduous tree species. Ecology, v. 48, p. 498-499, 1967.

JENSEN, W. A. Botanical histochemistry: principles and practice. San Francisco: W. H. Freman \& Co, 1962. 408 p.

JOHANSEN, D. A. Plant microtechnique. New York: McGraw-Hill, 1940. 523 p.

JONHSON, H. B. Plant pubescence: an ecological perspective. Botanical Review, v. 41, p. 233-258, 1975.

R. Árvore, Viçosa-MG, v.27, n.6, p.759-767, 2003
JUDD, W. S. et al. Plant systematics: a phylogenetic approach. Massachusetts: Sinauer Associates, 1999. $456 \mathrm{p}$.

KRAUS, J. E.; ARDUIN, M. Manual básico de métodos em morfologia vegetal. Seropédica, RJ: EDUR, 1997. $198 \mathrm{p}$.

LEAL FILHO, N. Caracterização do banco de sementes de três estádios de uma sucessão vegetal na Zona da Mata de Minas Gerais. 1992. 116 f. Dissertação (Mestrado em Ciência Florestal) - Universidade Federal de Viçosa, Viçosa, 1992.

LERSTEN, N. R. Morphology and distribution of colleters and crystals in relation to the taxonomy and bacterial leaf nodule symbiosis of Psychotria (Rubiaceae). American Journal of Botany, v. 61, n. 9, p. 973-981, 1974.

MARIANI, J. Les cafiers. Structure anatomique de la Feuille. Lons-le Saunier: L. Declume, 1908. 140 p.

METCALFE, C. R.; CHALK, L. Anatomy of the Dicotyledons. Oxford: Clarendon Press, 1950. v.2. 1500 p.

MORRETES, B. L. Contribuição ao estudo da anatomia das folhas de plantas do Cerrado. II. Boletim da Faculdade de Filosofia, Ciências e Letras da Universidade de São Paulo 305, Botânica, v. 22, p. 209-244, 1966.

MORRETES, B. L. Contribuição ao conhecimento da anatomia ecológica de plantas de Cerrado de Emas - SP e da Caatinga Amazônica do km 62 da rodovia BR 171. 1980. 276 f. (Tese Livre-Docência) - Universidade Estadual de São Paulo, São Paulo, 1980.

NASCIMENTO, M. V. O.; GOMES, D. M. S.; VIEIRA, R. C. Anatomia foliar de Bathysa stipulata (Vell.) Presl. (Rubiaceae). Revista Unimar, v. 18, n. 2, p. 387-401, 1996.

NUNES, E. C. M.; MARIATH, J. E. D.; OLIVEIRA, P. L. D. Morfologia e anatomia da folha de espécies da secção III (sensu Ehrendorfer) do gênero Relbunium (Rubieae Rubiaceae). Iheringia, v. 44, p. 113-149, 1994.

PEREIRA, C.A. Plantas tóxicas e intoxicações na veterinária. Goiânia: UFG, 1992. 279 p.

RADFORD, A. E. et al. Vascular plans systematics. New York: Harper \& Row Publishers, 1974. 891 p. 
RIZZINI, C. T. Tratado de fitogeografia do Brasil. São Paulo: Humanismo, Ciência e Tecnologia. 1976. 520 p.

RIZZINI, C. T. Tratado de fitogeografia do Brasil: aspectos ecológicos, sociológicos e florísticos. São Paulo: Âmbito Cultural, 1992. 747 p.

ROBBRECHT, E. Introduction to advances in Rubiaceae macrosystematics. Opera Botanica Belgica, v. 6, p. 7-18, 1993.

SALATINO, A.; MONTENEGRO, G.; SALATINO, M. L. F. Microscopia eletrônica de varredura de superfícies foliares de espécies lenhosas do cerrado. Revista Brasileira de Botânica, v. 9, n. 2, p. 117-124, 1986.

SCHUMANN, K. Rubiaceae. In: ENGLER, A.; PRANTL, K. Die Natürlichen Pflanzenfamilien, v. 4, n. 4, p. 1-156, 1891.

SOLEREDER, H. Systematic anatomy of the Dicotiledons. Oxford: Clarendon Press, 1908. 1182 p.

STANDLEY, P. C. Rubiaceae. In: MACBRIDE, J. F. Flora of Peru. Field Museum of Natural History, v. 13, n. 6, p. 3- 261, 1936.

STANDLEY, P. C. Flora of Costa Rica: Rubiaceae. Field Museum of Natural History, v. 18, p. 1264-1380, 1938.

STEYERMARK, J. A. Palicourea. In: MAGUIRE, B. M. et al. Flora of the Guayana Highlands. Memoirs of New York Botanical Garden, v. 23, p. 717-777, 1972.

TAYLOR, C. M. Revision of Palicourea (Rubiaceae) in Mexico and Central America. Systematic Botanical Monograph, v. 26, p. 1-102, 1989.

TAYLOR, C. M. Revision of Palicourea (Rubiaceae: Psychotrieae) in the West Indies. Moscosoa, v. 7, p. 201241, 1993.

TAYLOR, C. M. Overview of the Psychotrieae (Rubiaceae) in the Neotropics. Opera Botanica Belgica, v. 7, p. 261270, 1996.
TAYLOR, C. M. Conspectus of the genus Palicourea (Rubiaceae: Psychotrieae) with the description of some new species from Ecuador and Colombia. Annals of the Missouri Botanical Garden, v. 84, p. 224-262, 1997.

UPHOF, J. C. Plant hairs. Gebruder Borntraeger Berlin: Nikjolassee, 1962. 292 p.

VIEIRA, R. C. Diodia radula (Willd. et Holffm) Cham. et Schltdl. (Rubiaceae). Anatomia foliar. Revista Brasileira de Biologia, v. 46, n. 3, p. 667-674, 1986.

VIEIRA, R. C. Tocoyena bullata (Vell.) Mart. (Rubiaceae) Anatomia Foliar. Rodriguesia, v. 66, n. 40, p. 33-39, 1988.

VIEIRA, R. C.; GOMES, D. M. S.; FERRAZ, C. L. A. Anatomia foliar de Psychotria nuda Wawra e Psychotria leiocarpa Mart. (Rubiaceae). Hoehnea, v. 19, n. 1/2, p. 185-195, 1992.

VOLPATO, M. M. L. Regeneração natural em uma floresta secundária no domínio de Mata Atlântica: Uma análise fitossociológica. 1994. 123 f. Dissertação (Mestrado em Ciência Florestal) - Universidade Federal de Viçosa, Viçosa, 1994.

WATSON, R. W. Effect of cuticular hardening on the form of epidermal cells. New Phytologist, v. 41, p. 223-229, 1942.

WEAVER, J. E.; CLEMENTS, S. F. E. Ecologia vegetal. Buenos Aires: Acme Agency Soc. Resp., 1944. 667 p.

WERKER, E. Trichome diversity and development. In: HALlahAN, D. L.; GRAY, J. C. (Eds.) Plant Trichomes. London: Academic Press, 2000. p. 1-30. (Advances in Botanical Research, 31)

WILKINSON, H. P. The plant surface. In: METCALFE, C. R.; CHALK, L. (Eds.) Anatomy of the Dicotyledons. Systematic Anatomy of the leaf and stem. Oxford: Clarendon Press, 1979. v.1. p. 97-165.

WYLIE, R. B. Principles of foliar organization shown by sunshade leaves from ten species of deciduous dicotyledon trees. American Journal of Botany, v. 38, p355-361, 1951. 